\title{
CAMPOS DE URNAS EN LA MESETA ORIENTAL: NUEVOS DATOS SOBRE UN VIEJO TEMA
}

\author{
URNFIELDS IN THE EASTERN MESETA: NEW FINDS ON AN OLD TOPIC
}

\author{
M. ${ }^{a}$ LUISA CERDEÑO $\left(^{*}\right)$ \\ FÁTIMA MARCOS $(*)$ \\ TERESA SAGARDOY $(*)$
}

\section{RESUMEN}

Los recientes descubrimientos arqueológicos, acompañados de dataciones radiocarbónicas muy antiguas, realizados en la necrópolis de incineración de Herrería (Guadalajara, España) constituyen una interesante información sobre la llegada del ritual incinerador, asociado a los Campos de Urnas, a la Meseta oriental. Este territorio fue la zona nuclear de la posterior Celtiberia histórica, por lo que creemos que dichos elementos culturales jugaron un destacado papel en la gestación de la cultura celtibérica.

\begin{abstract}
The recent archaeological discoveries along with the radiocarbon dates from the cremation cemetery Herreria (Guadalajara, Spain) are new evidence of the arrival of Urnfield people in the eastern Meseta. Assuming that this interior area was a part of the historic Celtiberian region we think these cultural influences played an important role in the origins of the Celtiberian culture.
\end{abstract}

Palabras clave: Incineración. Campos de Urnas. Península Ibérica. Fechas radiocarbónicas. Orígenes cultura celtibérica.

Key words: Cremation ritual. Urnfields of the Iberian Peninsula. Radiocarbon dates. Origins of Celtiberian culture.

\section{INTRODUCCIÓN}

La información que está proporcionando la necrópolis de Herrería (Guadalajara) creemos que

(*) Dpto. de Prehistoria. Universidad Complutense. 28040 Madrid. Correo electrónico: mluisac@ghis.ucm.es

Recibido: 12-V-02; aceptado: 3-IX-02. constituye un importante testimonio de la presencia del ritual incinerador, asociado a gentes de Campos de Urnas; en el reborde oriental de la Meseta durante el periodo del Bronce Final. La necrópolis ha proporcionado tres fases sucesivas de utilización que demuestran un prolongado uso a lo largo de casi un milenio, hecho bastante excepcional en el panorama de los hallazgos funerarios. A través de su estratigrafía vertical podemos conocer los cambios que se produjeron en el ritual funerario y, teniendo en cuenta que "la muerte es ante todo un acontecimiento sociológico" (Thomas 1975: 33), se nos brinda la oportunidad de reconstruir secuencialmente la evolución cultural de los grupos allí asentados, desde el Bronce Final hasta bien entrada la Edad del Hierro.

Las conclusiones que ahora presentamos debemos considerarlas provisionales ya que los trabajos de campo aún no han finalizado y la mayor parte de la documentación se encuentra todavía en proceso de análisis y estudio pormenorizado. Solamente vamos a exponer de manera puntual los aspectos materiales más relevantes del yacimiento que permiten una adscripción cronológica y cultural bastante sólida. Tras las dos primeras campañas de excavación, presentamos una breve noticia de los hallazgos efectuados en una reunión sobre arqueología provincial (Cerdeño et al. e.p.).

Herrería está enclavada en la comarca de Molina de Aragón, en el extremo más oriental de la provincia de Guadalajara, lindando con las provincias de Zaragoza y Teruel, territorios que integraban la Celtiberia histórica y que hoy constituyen una de las mejores fuentes de información arqueológica sobre sus antiguos habitantes, debido a los numerosos yacimientos en ellos descubiertos. Iniciamos los 


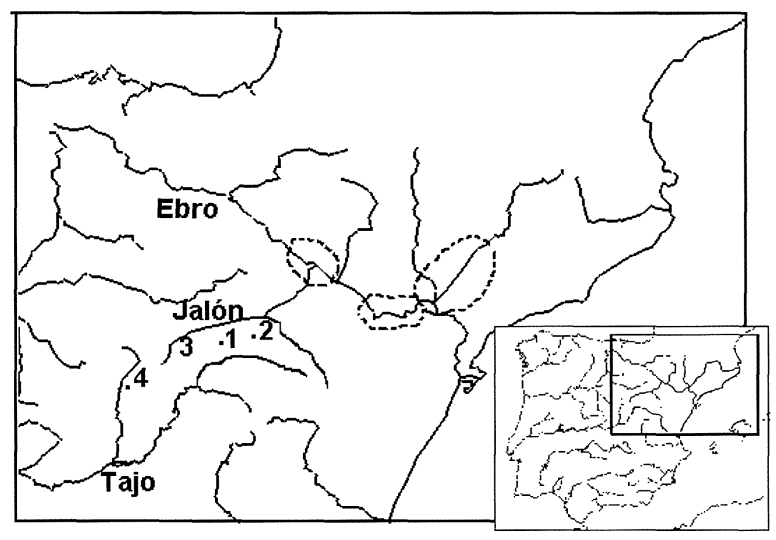

Fig. 1. Situación de los yacimientos del Bronce Final, con cerámicas incisas, en el norte de la provincia de Guadalajara: 1: Necrópolis de Herrería. 2: Poblado de Fuente Estaca. 3: Poblado de La Era del Locón. 4: Poblado de Pico Buitre. Círculos: áreas tumulares ilerdense y bajoaragonesa.

trabajos en la necrópolis en 1998, dentro del proyecto de investigación que desde hace tiempo centramos en las fases más antiguas de la cultura celtibérica, cuyas fases mejor conocidas se desarrollaron durante la Edad del Hierro pero cuyos precedentes se remontan más atrás en el tiempo (Fig. 1).

Poco se sabía sobre el Bronce Final y su transición a la Edad del Hierro en esta zona geográfica, pero estudios recientes están perfilando un nuevo panorama (Valiente 1984; Valiente y Velasco 1986; García Huerta 1989; Crespo y Cuadrado 1990; Barroso 1999, 1993; Martínez Sastre 1992, Martínez Naranjo 1997; Arenas 1999; Cerdeño y Juez 2002) en el que puede ocupar un lugar importante esta nueva necrópolis. Siempre hemos supuesto que en la comarca de Molina pudieron coincidir diferentes influencias culturales, entre ellas la de grupos de Campos de Urnas llegados desde el valle del Ebro que, como rutinariamente se afirma, debieron contactar con poblaciones autóctonas preexistentes en la zona a pesar de que este substrato indígena, por el momento, está muy poco o nada documentado. Nuestra hipótesis se apoya en los nuevos datos arqueológicos y en las nuevas cronologías radiocarbónicas que inclinan a seguir pensando en el importante papel que estos grupos de urnenfelder, originariamente procedentes del otro lado de los Pirineos, desempeñaron en la gestación de los grupos prerromanos meseteños.

Recordemos que la llegada de los Campos de Urnas al Noreste de la Península Ibérica fue uno de los temas más tratados de nuestra Prehistoria final desde las primeas décadas del siglo XX, aunque su presencia en la Meseta nunca se aceptó claramente (Bosch Gimpera 1921, 1939; Maluquer 1945, 1954, 1971; Almagro Basch 1952; Tovar 1957; Beltrán 1960) y la percepción de las novedades culturales se circunscribía al cuadrante nororiental basándose en los hallazgos obtenidos en yacimientos catalanes, aragonesas y, algo más tarde, del norte levantino (Almagro Gorbea 1977)

Muchos autores siguieron interesados en este tema, especialmente en las regiones más directamente afectadas (Maya 1978; Pons 1989; Pons y Maya 1988,. Rovira 1991) y se realizaron algunas buenas síntesis sobre el estado de la cuestión (Neumaier 1995; Maya 1998M; Ruiz Zapatero 1985, 2001) siempre referidas al ámbito catalano-aragonés y en el caso de que se aludiera a los territorios meseteños se proponían cronologías bastante recientes (Royo 1990), posiblemente por la deficiente y antigua información que existía sobre la Meseta y por la escasa repercusión que tenían los pocos datos conocidos. Estas ideas se mantuvieron a pesar de que los tempranos testimonios obtenidos en los valles de los afluentes del Ebro por su margen derecha (por ejemplo en el área caspolina o en las cercanías de la desembocadura del Jalón) y en las zonas levantinas septentrionales hacían verosímil pensar que dichas influencias también hubieran rozado los territorios de la Meseta nororiental.

A finales de los años 70 comenzamos nuestros estudios en yacimientos celtibéricos de la provincia de Guadalajara buscando los orígenes de unas características culturales cuyo auge se situaba a partir del siglo $\mathrm{V}$ a.C. pero que, sin duda, habían tenido un amplio precedente, entonces muy poco conocido. Desde que Bosch Gimpera (1921) en su relevante trabajo sobre los elementos celtas peninsulares catalogase las necrópolis de incineración de la Meseta como "posthallstáticas", no se había vuelto a cuestionar la posible antigüedad de algunos elementos formales en ellas documentados.

En los primeros momentos de nuestra investigación desconocíamos muchos datos y nuestras argumentaciones no eran demasiado sólidas, pero pronto percibimos que existían rasgos culturales, tanto en los materiales de la vieja colección Cerralbo, como en los yacimientos que empezábamos a excavar, cuyas características hacían volver los ojos hacia el entorno geográfico y cultural del valle del Ebro y permitían plantear cronologías más antiguas. Esto pareció claro cuando descubrimos los túmulos de la necrópolis de Sigüenza, en cuya pri- 
mera valoración ya proponíamos abandonar el sesgado y determinante titulo de "posthallstático" para este tipo de yacimientos.

Poco después accedíamos a la incompleta información de la necrópolis tumular de Molina que de nuevo recordaba al mundo bajoaragonés, al tiempo que especulábamos con la alta fecha radiocarbónica obtenida en el castro de La Coronilla (950 sin cal.) que, aunque única y por ello poco sólida, hizo que volviéramos a plantear la posible presencia de Campos de Urnas en el oriente meseteño (Cerdeño 1985-86; Cerdeño y García Huerta 1992). Esta discutible datación sigue siendo utilizada por otros autores como argumento de la vinculación de los territorios interiores con el fenómeno de los C.U. (Valiente y Velasco 1986; Crespo y Cuadrado 1990; Barroso 1999). Hoy se conocen más pruebas materiales para sostener esta hipótesis pues aparte de los llamados "poblados de ribera", entre los que destaca el mencionado Pico Buitre, se han localizado auténticos exponentes de los Campos de Urnas en las viviendas de Fuente Estaca (Guadalajara), donde se encontraron cerámicas bicónicas con decoraciones acanaladas, incisas, excisas, con cordones y algunas peinadas, así como una fíbula de pivote, todo ello situado por una datación de C-14 en el siglo IX a.C. (Martínez Sastre 1992).

El conocimiento sobre la cultura celtibérica es ahora más amplio que entonces, buena muestra de ello son los 5 Symposia realizados hasta el momento sobre el tema, y casi todos los especialistas admiten que los Campos de Urnas fueron uno de los principales componentes de esta cultura prerromana, idea ahora reforzada por su presencia confirmada en dicho territorio histórico. Ello no invalida los evidentes aportes que desde el ámbito levantino llegaron, siglos más tarde, hasta el reborde oriental de la Meseta (fin del siglo VII-VI a.C.), documentados repetidamente en los niveles del Celtibérico Antiguo de casi todos los yacimientos excavados durante los últimos años.

\section{DATOS ARQUEOLÓGICOS}

En la necrópolis de Herrería se han identificado claramente tres momentos sucesivos de ocupación (Tab. 1), perfectamente definidos en la estratigrafía vertical que conserva el yacimiento y que demuestra una elección intencionada y reiterada del lugar durante varios siglos, quizás por su consideración de sagrado.
Se ha constatado una ocupación superior a la que denominamos fase Herrería III, algunos de cuyos materiales indican una cronología aproximada entre los siglos VI/V a.C., al margen de otro uso anterior, conocido por el material revuelto de superficie, que parece apuntar al siglo IV-III a. C., aunque en este trabajo no vamos a comentar estos últimos momentos de utilización ya que su cronología más reciente los aleja del motivo de discusión que ahora presentamos. Nos centraremos exclusivamente en el comentario de las dos primeras fases de ocupación (Herrería I y II), puesto que sus características y cronología permiten incluirlas en el ámbito cultural de los Campos de Urnas Antiguos.

HERRERÍA I: Denominamos así a la ocupación inicial de este espacio funerario que ha dejado como huella una necrópolis organizada, con un número de tumbas bastante elevado, todas de incineración pero sin ajuar material y con una estela de piedra

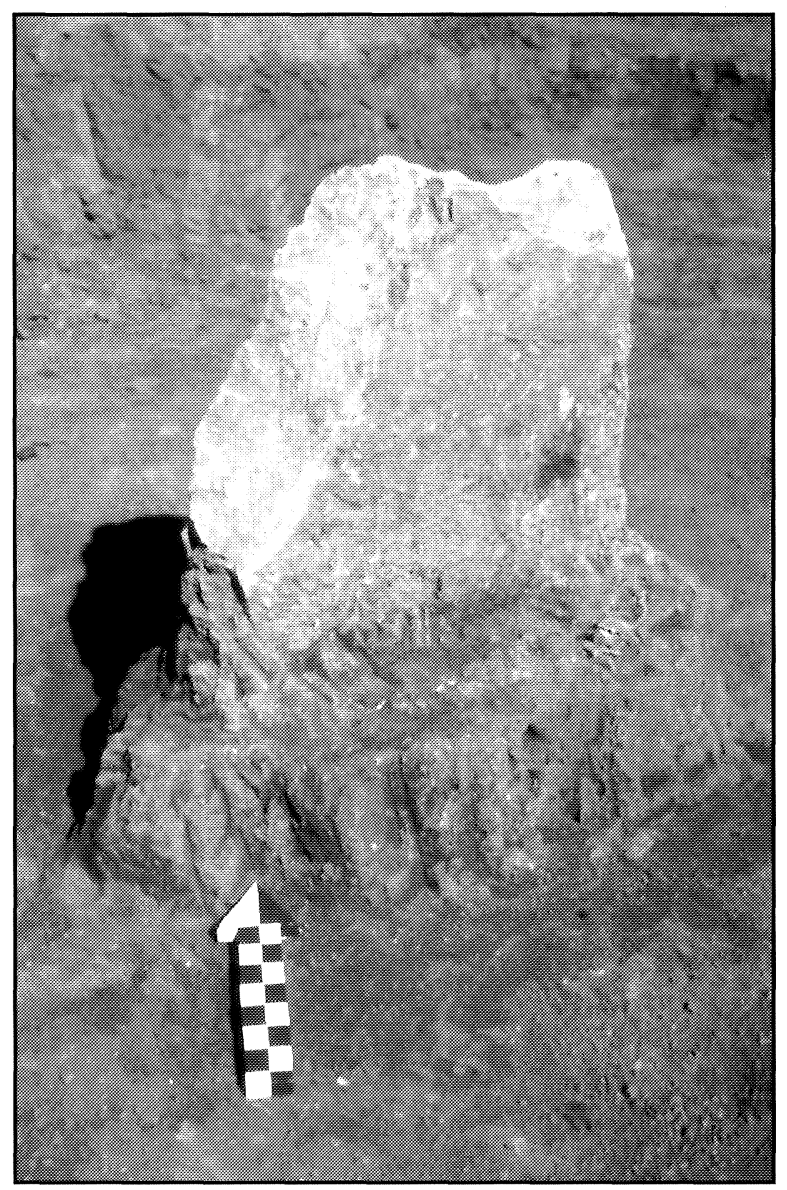

Fig. 2. Tumba n. ${ }^{\circ} 202$, señalizada con una estela de piedra, del nivel inferior de la necrópolis de Herrería. 
clavada verticalmente en el suelo señalizando la mayoría de ellas. Las estelas tienen forma prismática irregular y oscilan entre los 30 y $60 \mathrm{~cm}$ de altura (Fig. 2 ).

Hasta el momento se han localizado 39 enterramientos extendidos a lo largo de una superficie de aproximadamente $400 \mathrm{~m}^{2}$. Los restos de la cremación, efectuada en algún lugar aparte, se introdujeron en hoyos de forma ovalada muy bien delimitados, de unos $25 \mathrm{~cm}$. de eje y una potencia en torno a los $20 \mathrm{~cm}$. A partir de los huesos cremados, tras una observación preliminar de su color y textura, podemos deducir que las cremaciones se realizaron a elevadas temperaturas y con buena ventilación, presumiblemente en una pira al aire libre.

Las sepulturas de esta fase carecen de ajuar, a excepción de la tumba 10/98 en la que sobre la cremación aparecieron depositadas una serie de pequeñas piedras claramente seleccionadas, entre las que se encontraba un hacha pulimentada y un colgante de piedra, o de algunas otras en las que se depositaron uno o dos guijarros en la base de la estela.

En cuanto a la posible ordenación intencionada de las tumbas, parece que se orientan en dirección norte-sur, pero aún es pronto para pronunciarnos a este respecto ya que acabamos de iniciar un proyecto de investigación, en colaboración con el Departamento de Física de la Tierra y Astronomía I de la Facultad de Ciencias Físicas de la Universidad Complutense de Madrid, durante el que se están realizando una serie de mediciones y cálculos encaminados a determinar la posible intencionalidad de la disposición de las estelas.

También se han encontrado otro tipo de señalizaciones, consistentes en pequeñas piedras clavadas en el suelo sin restos de incineración debajo, situadas en lugares distantes dentro del área necropolitana. Bajo uno de ellos se conservaban restos de madera, quizás de un poste, y otros tres están formados por varias piedras de pequeño tamaño, colocadas en ángulo o en círculo, debajo de una de los cuales apareció la mitad de una mandíbula de bóvido, clavada verticalmente en el suelo. De este nivel de ocupación se han recogido muestras de huesos cremados y de carbones para el análisis radiocarbónico.

HERRERÍA II: Denominamos así a la segunda fase de utilización de la necrópolis, identificada a través de las 133 sepulturas excavadas hasta este momento. Durante esta fase parecen identificarse dos variaciones formales.

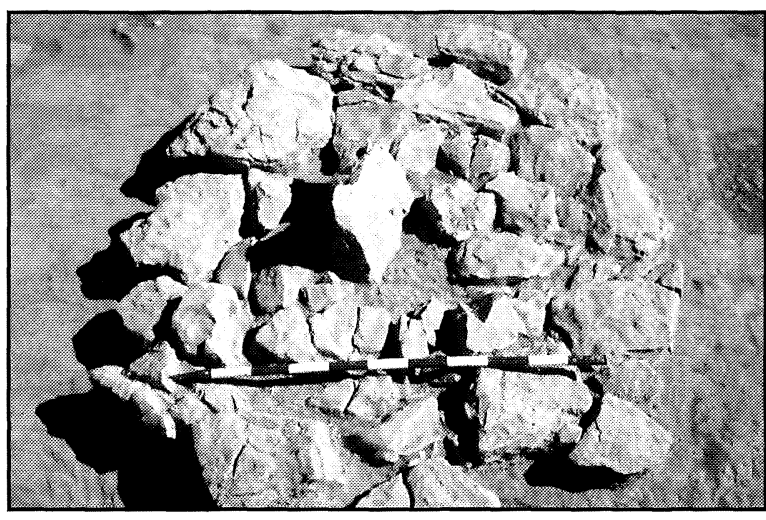

Fig. 3. Sepultura tumular n. ${ }^{\circ} 100$ de la necrópolis de Herrería.

En el primer caso, se realizaron túmulos circulares de entre 1 y 2,5 m de diámetro, construidos con piedras grandes dispuestas en una sola hilada y en cuyo centro estaba depositada la incineración. Algunos de estos túmulos tenían una estela de piedra en el centro, como la tumba 100/00, actualmente expuesta al aire libre delante del pequeño Museo de Herrería (Fig. 3). Entre estos túmulos de incineración se han descubierto cuatro túmulos conteniendo inhumaciones (tumbas n. ${ }^{\circ}$ 57, 58, 222, 233). Estos monumentos son generalmente más grandes, rectangulares o redondos, construidos a base de grandes lajas verticales o ligeramente inclinadas, a modo de grandes cistas. Además de estos cuatro inhumados, apareció el esqueleto de un neonato enterrado en un túmulo circular (sepultura n. ${ }^{\circ} 43$ ), junto a una incineración.

En el segundo caso, representando quizás otro momento de uso o simplemente una diferenciación social intencionada, cambia la forma de las estructuras pétreas y se observa un encachado continuo ocupando determinados espacios, separados entre sí por pasillos de tierra sin enterramientos.

Se ha observado en muchas sepulturas de esta fase que los restos óseos cremados son abundantes, pudiéndose deducir que las piras no alcanzaron demasiada temperatura o los individuos estuvieron sometidos al fuego durante poco tiempo y que, después, la recogida de los restos fue exhaustiva y metódica: el cráneo aparece bastante completo en posición anatómica en el fondo del hoyo, seguido de las vértebras y por último de las extremidades.

Los ajuares encontrados en todas las tumbas de esta fase son especialmente escasos. Se localizaron cerámicas a mano de pastas finas, formas bicónicas, en su mayoría lisas, salvo algunas de ellas con de- 


\begin{tabular}{|c|c|c|}
\hline $\begin{array}{l}\text { HERRERIA I } \\
\text { (39 seps.) }\end{array}$ & Sg. XI a.C. (XIII cal.) & $\begin{array}{c}\text { Incineración } \\
\text { Estelas de señalización } \\
\text { Ausencia de ajuar }\end{array}$ \\
\hline $\begin{array}{l}\text { HERRERÍA II } \\
\text { (133 seps.) }\end{array}$ & Sg. IX a.C. (X cal) & $\begin{array}{c}\text { Incineración e } \\
\text { inhumación } \\
\text { Túmulos con/sin estela } \\
\text { central } \\
\text { Empedrados tumulares } \\
\text { Cerámicas lisas e } \\
\text { incisas } \\
\text { Remaches de bronce } \\
\text { Anillas y remaches de } \\
\text { bronce } \\
\text { Cuenta de ámbar }\end{array}$ \\
\hline $\begin{array}{c}\text { HERRERÍA } \\
\text { IIIa } \\
\text { IIIb } \\
\text { (83 seps.) }\end{array}$ & $\begin{array}{l}\text { Sg. fin VI/V a.C. } \\
\text { IV-III a.C. }\end{array}$ & $\begin{array}{c}\text { Incineración } \\
\text { Sepulturas en hoyo } \\
\text { Empedrados tumulares } \\
\text { Ajuares generalizados: } \\
\text { cerámica mano y torno, } \\
\text { objetos de bronce; } \\
\text { armas de hierro, cuentas } \\
\text { collar, etc. }\end{array}$ \\
\hline
\end{tabular}

Tab. 1. Fases de la necrópolis de Herrería.

coración incisa cuyos motivos principales, dispuestos en bandas horizontales, con triángulos rellenos y espigas (Fig. 4). Existen también algunos fragmentos de cerámicas de paredes finas con mamelones así como fragmentos de recipientes de paredes gruesas con decoración de cordones. Los objetos metálicos están representados por anillas y por numerosos remaches de bronce con cabeza semiesférica.

Esta breve descripción de los hallazgos más relevantes creemos que es suficiente para valorar el indudable interés que ofrece el yacimiento. No deja, sin embargo, de mostrar ciertas peculiaridades pues aparte de los significativos ritos funerarios utilizados y la variada tipología de los enterramientos, se han encontrado muy pocas piezas de ajuar y no están presentes algunos de los fósiles-guía que acompañan a las cremaciones antiguas y son aceptados de forma genérica como exponentes de la presencia de Campos de Urnas. A pesar de ello, defendemos su adscripción a dicho contexto cultural pues compartimos la idea de que "la presencia del ritual de la incineración es condición básica de pertenencia a los Campos de Urnas" (Neumaier 1995: 54). Y ello a pesar de que también se ha interpretado el rito de la incineración desvinculado de los Campos de Urnas cuando se han podido rastrear huellas de cremaciones parciales en algunas sepulturas de culturas anteriores (González Prats 2002: 393), aunque creemos que los casos presentados no son

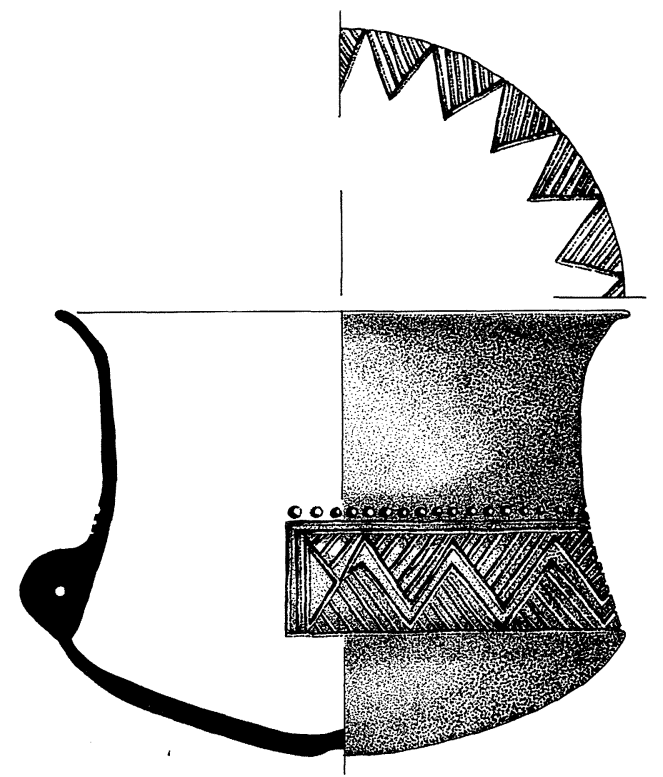

Fig. 4. Cuenco de cerámica a mano con decoración incisa procedente del nivel tumular de la necrópolis de Herrería.

ejemplo de una práctica ritual generalizada comparable a la que ahora comentamos.

La primera utilización de la necrópolis (Herrería I), fechada en el siglo XII a.C. (XIII cal.), muestra ya un espacio intencionadamente elegido y bien organizado en el que se usaba de modo exclusivo la cremación del cadáver con la posterior deposición de los restos en un hoyo en el suelo sin urna cerámica y señalizado con una tosca estela de piedra clavada verticalmente, paisaje difícil de paralelizar con ningún otro yacimiento conocido de este período.

El rito de la incineración y los enterramientos individuales depositados en necrópolis organizadas sabemos que fue una novedad cultural introducida desde otros lugares hasta el territorio meseteño, pero el uso de estelas de piedra señalando cada una de esas tumbas no tiene precedente conocido en etapas anteriores, ni dentro ni fuera del ámbito peninsular. Sin embargo, sí se conocen ejemplos posteriores representados en las estelas de piedra de las necrópolis celtibéricas de los siglos V-IV a.C., sin que tampoco se haya explicado suficientemente su posible significado socio-religioso o su origen crono-cultural. Las estelas decoradas con jinetes, armas, etc. de la época de la conquista romana, repartidas por el territorio del Bajo Aragón (Galán 1994: 99), creemos que no mantienen relación directa con las que ahora estudiamos y, en cualquier caso, ofrecen una cronología de casi un milenio después. 
Esta primera ocupación resulta, pues, muy significativa puesto que sus fechas absolutas son sincrónicas a las manejadas en todas las necrópolis de Campos de Urnas Antiguos del noreste peninsular, mientras que sus características formales muestran algunas diferencias notables.

Por su parte, la fase Herrería II, fechada en el siglo IX a.C cal., sí ofrece paralelos formales muy próximos con las necrópolis de incineración de las áreas del Segre-Cinca y del Bajo Aragón. No seremos exhaustivas en los paralelos formales de cada uno de los elementos descubiertos, pero baste recordar algunos casos significativos bien fechados y bien estudiados desde hace tiempo.

Nos referimos, por ejemplo, a la necrópolis ilerdense de La Colomina (Ferrández et al. 1991) cuyos túmulos circulares, con o sin estela central, ofrecen un gran paralelismo con los hallados en Herrería. Baste observar sus túmulos 2, 7 y 14 para comprobar su semejanza con los meseteños, especialmente con nuestra sepultura 100/00. Aparte de los monumentos funerarios, algunas características de los ajuares también son coincidentes, así como la escasez generalizada de piezas metálicas y las decoraciones incisas de algunas cerámicas (Fig. 5, 6). Bien es cierto que, en nuestro caso, faltan las decoraciones acanaladas. Este yacimiento fue fechado, según la cronología convencional basada en la tipología de los materiales, entre los siglos IX y VII a.C. (Ferrández et al. 1991: 139).

En la necrópolis del Coll del Moro de Gandesa (Rafel y Hernández 1992; Rafel 1993) se hallaron estructuras de piedra también muy similares. Aquellos túmulos, siempre sobre sepulturas de incineración, eran en su mayoría circulares a veces con estela central y en algunos de ellos se había depositado un vaso cerámico encima del monumento sepulcral. Están fechados arqueológicamente entre los años 800-550 a.C.

El poblado y la necrópolis de La Loma de los Brunos fueron considerados como exponentes típicos de los Campos de Urnas de Aragón (Eiroa 1982) y fueron datados arqueológicamente en torno al año 1000 a.C., aunque continuaron su existencia hasta el 500 a.C. En el cementerio se localizaron 18 túmulos, casi todos de planta circular, sobre enterramientos de incineración. Aunque su investigador consideraba que existían muy pocos datos sobre las etapas precedentes, creyó que los monumentos podrían tener relación con el tardío mundo megalítico pirenaico y podían constituir una tradición local incorporada a las nuevas influencias de los Campos de Urnas (Eiroa 1982: 32). En cuanto al ajuar material recuperado en las tumbas, cabe destacar la casi ausencia de objetos metálicos, sólo representados por algunas agujas y anzuelos, mientras que entre las cerámicas destaca algún fragmento con decoración acanalada y excisa además de muchos recipientes de paredes gruesas con decoraciones plásticas.

Pero sin duda, es la necrópolis de Los Castellets I y II de Mequinenza (Zaragoza) la que ofrece mayores semejanzas con Herrería II (Tab. 2). Sus más de cien sepulturas ofrecieron una variada tipología tumular (Royo 1994, 1994-96) prácticamente idéntica a la del grupo ilerdense y ahora podemos decir que también similar a la nuestra. No sólo resulta sorprendente el parecido morfológico de los túmulos, asociados siempre a enterramientos de incineración, sino también la presencia entre ellos de algunos enterramientos de inhumación protegidos por monumentos pétreos más grandes, en ocasiones a modo de cista. El investigador de este yacimiento aragonés lo consideró exponente de la primera presencia y posterior desarrollo de los Campos de Urnas en el Noreste y un claro ejemplo del proceso de acultu-ración sufrido por las poblaciones indígenas preexistentes (Royo 1994-96: 106). A la información arqueológica hay que añadir las fechas de C-14 obtenidas en algunos de sus túmulos, detalladas en el apartado siguiente, que sitúan sus primeros enterramientos en torno al año 1100 a. C. (Royo 199496: 98).

\begin{tabular}{|c|}
\hline Similitudes entre Herrería II y Castellets I y II \\
\hline $\begin{array}{c}\text { Rito incineración. No ustrinium. Presencia de carbón y } \\
\text { cenizas }\end{array}$ \\
\hline Huesos lavados y seleccionados \\
\hline Túmulos incineración circulares con y sin estela central \\
\hline Rito inhumación bajo túmulos grandes \\
\hline Arandelas y remaches de bronce \\
\hline Ausencia de objetos de hierro \\
\hline
\end{tabular}

Tab. 2.

Podríamos alargar los paralelismos observados respecto a las restantes necrópolis tumulares ilerdenses (Torre Filella, Roques de Sant Formatge, Pedrós, etc.) pero creemos que es suficiente con mencionar aquellas que geográficamente se encuentran más próximas. 


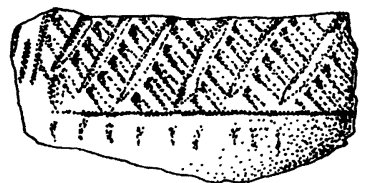

1

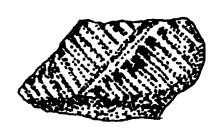

2

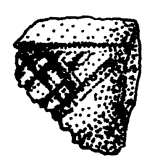

3

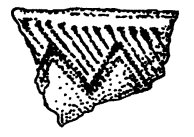

4

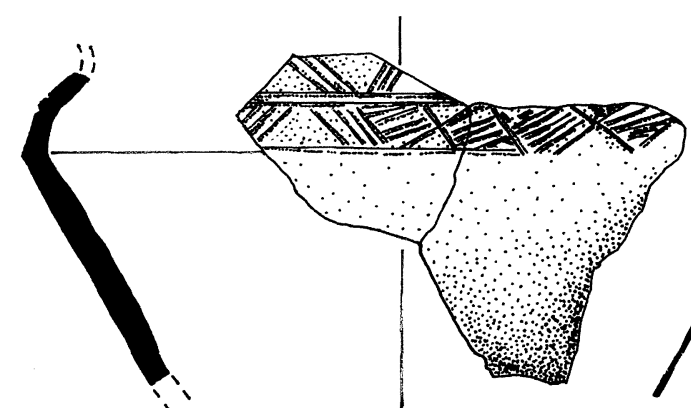

5
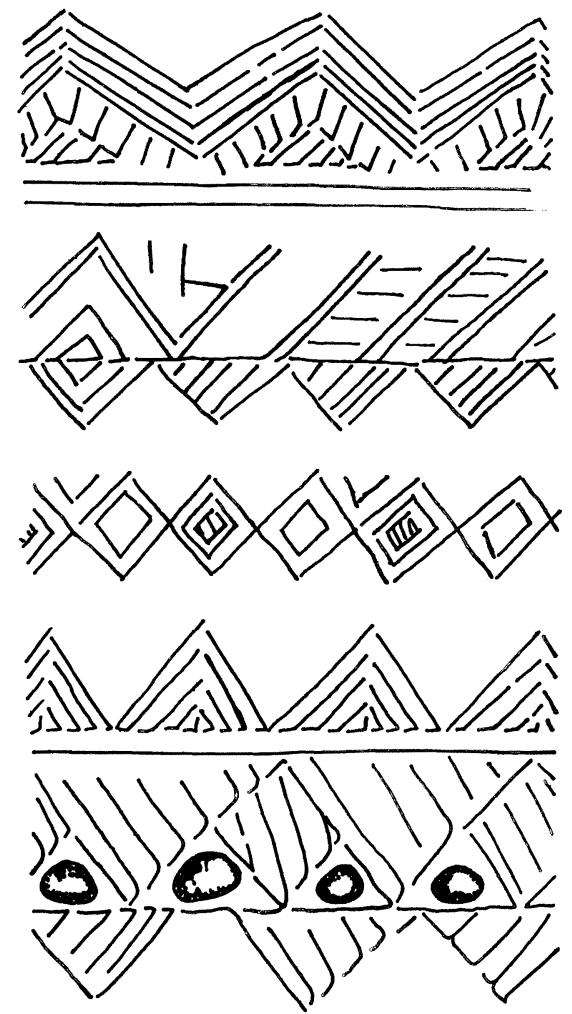

7

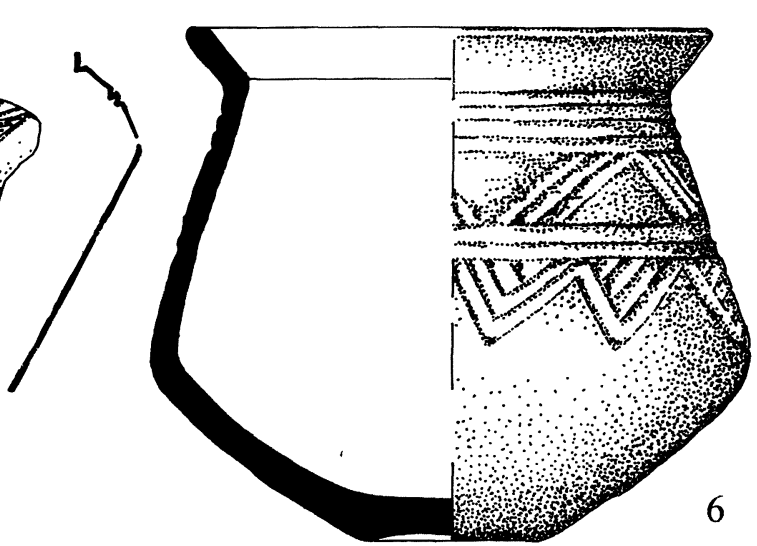

0 $5 \mathrm{~cm}$.
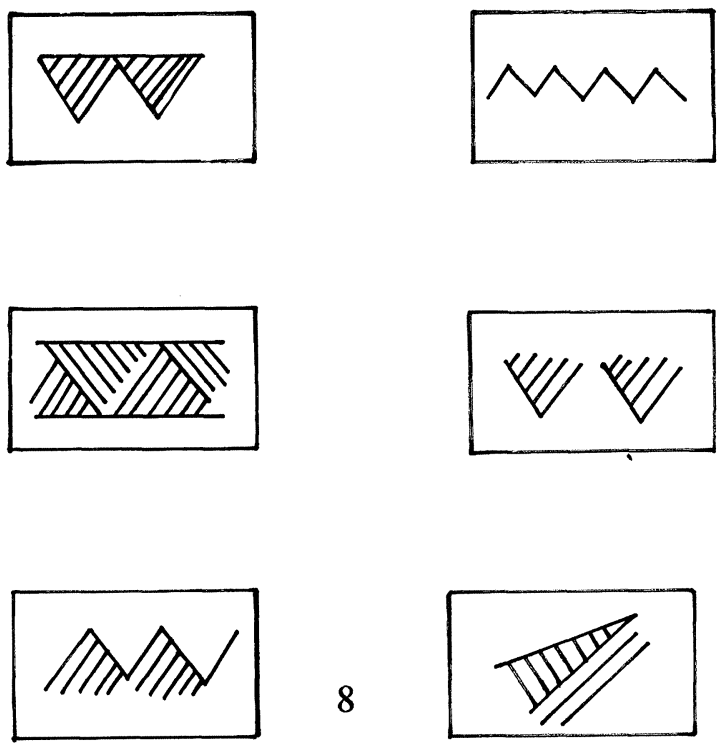

Fig. 5. 1-4: Cerámicas a mano con decoración incisa del poblado de Fuente Estaca (dibujos sobre fotografías de Martínez Sastre 1992). 5: Cerámica a mano con decoración incisa procedente de la Era del Locón (según Martínez Naranjo 1997). 6: Urna fabricada a mano, con decoración incisa, procedente del túmulo 100 de la necrópolis de La Colomina (según Ferrández et al. 1991). 7: Decoraciones incisas de las cerámicas fabricadas a mano del poblado de Palermo (según Pelicer 1987). 8: Decoraciones incisas de las cerámicas a mano del poblado de Pico Buitre (según Barroso 1993). 
Aparte de la estrecha vinculación formal que ofrecen los monumentos funerarios, hay otros elementos a considerar. En la época de los Campos de Urnas Antiguos la ausencia de objetos metálicos en las sepulturas es una constante repetida en casi todos los territorios estudiados, tanto en la Cataluña costera como en el valle del Segre-Cinca o en el Bajo Aragón, pudiéndose atribuir a una escasez de metal a nivel local o a una limitada producción que convertía a estas escasísimas piezas en objetos de consideración especial (Ferrandez et al. 1991: 135; Ruiz Zapatero 2001: 264). En Herrería I no se ha encontrado nada de metal y en Herrería II es realmente escaso puesto que, aunque se encuentra bronce en varias sepulturas, éste se reduce a algunas anillas y pequeños botones o remaches que presumiblemente formaban parte de las vestimentas del individuo enterrado.

El otro elemento material significativo para identificar la presencia de Campos de Urnas ha sido siempre la cerámica, especialmente la que ofrece formas bicónicas y decoración acanalada, convertida en su auténtico fósil guía y aceptada su presencia desde muy pronto, en torno al 1300 según la cronología calibrada (Castro et al. 1996: 182). Ni en Herrería I, ni en Herrería II se utilizaron urnas para depositar las cremaciones por lo que carecemos del principal identificador material, si bien se han podido recoger y reconstruir algunas cerámicas de perfil bicónico con decoración incisa y de cordones. La presencia de vasos incisos es frecuente durante el Bronce Final, tanto en necrópolis como en poblados a lo largo de todo el Languedoc, el Ampurdán y el Bajo Aragón.

Efectivamente, no sólo en las necrópolis aparecen los elementos materiales significativos, sino que también se conocen un buen número de poblados en los que han aparecido los mismos materiales, algunos bien fechados por $\mathrm{C} 14$, como podemos observar en el cuadro del siguiente apartado.

Nos parece interesante el poblado de Genó (Lérida) por tratarse de un habitat de nueva planta, con viviendas de disposición perimetral de planta rectangular, en el que han aparecido cerámicas bicónicas con decoración acanalada acompañadas de botones y agujas de bronce y brazaletes de lignito donde, a pesar de la posible existencia de elementos de substrato, su excavador lo consideró "el conjunto protourbano de C.U. Antiguos más interesante de Cataluña" (Maya et al. 2000: 171), contando sin duda con las altas fechas radiocarbónicas en torno al 1000 a.C.
Existen otros poblados bajoaragoneses fechados desde el Bronce Final, muchos asociados a necrópolis de incineración con enterramientos tumulares, algunos conocidos desde hace bastantes décadas y por ello no estudiados con detalle, en los que se documentaron viviendas rectangulares y cerámicas a mano con decoración acanalada, incisa y excisa, al tiempo que el metal encontrado era escasísimo. Podemos citar El Cabezo de Monleón, San Cristóbal de Mazaleón, Sancharancón, Záforas o Palermo IV (Beltrán 1963; Pellicer 1987), este último con cerámicas incisas muy semejantes a las de Herrería II (Fig. 5, 7). También son evidentes los paralelismos entre el Alto Ebro, La Rioja y el sur de Navarra con la Meseta oriental, siendo suficiente mencionar el yacimiento de Cortes de Navarra (Maluquer 1955, 1957; García 1994; Munilla y Gracia 1995) como una referencia obligada, dadas las semejanzas observadas.

Resumiendo todas estas comparaciones formales, comprobamos que muchas de las características materiales consideradas exponentes de los Campos de Urnas catalanes y aragoneses (incineración, túmulos, determinadas cerámicas, fechas desde fin del II milenio a.C., etc.) también están presentes en esta nueva necrópolis de la Meseta oriental y fueron elementos que, además, no se perdieron y perduraron en los castros y necrópolis del período Celtibérico Antiguo y en etapas posteriores, es decir, a lo largo de toda la Edad del Hierro (Tab. 3).

En el valle del Ebro y en relación directa con el mundo funerario descrito, ya hemos visto que se conocen muchos lugares de habitación ejemplificados en poblados de nueva planta situados en altu$\mathrm{ra}$, con viviendas rectangulares en disposición perimetral y un equipo material compuesto por cerámicas acanaladas, incisas y cordones, todos ellos fechados también desde el Bronce Final IIIa.

En la comarca molinesa no se conocen poblados en altura, con viviendas rectangulares ya organizadas, en momentos tan antiguos. De esta época, el habitat mejor conocido es el de Fuente Estaca (Embid), situado en una suave ladera en la cabecera del río Piedra, afluente del Jalón por su margen derecha, cuyos restos corresponden a varias cabañas de planta aproximadamente ovalada, una de las cuales conservaba los agujeros de los postes en uno de sus lados (Martínez Sastre 1992: 72). Los materiales en ellas recuperados son relevantes pudiéndose destacar un gran vaso bicónico con decoración acanalada, fragmentos de vasijas bicónicas sin decoración y fragmentos con decoración excisa e incisa, los

T. P., 59, n. ${ }^{\circ} 2,2002$ 
motivos de esta última, a base de zig-zag y triángulos rellenos, son casi idénticos a los encontrados en Herrería. El yacimiento se fechó en el siglo IX a.C. en base a la fecha radiocarbónica del $800 \pm 90$ a.C., sin calibrar (Fig. 5, 1-5, 8).

\begin{tabular}{|c|c|}
\hline $\begin{array}{l}\text { CRONOLOGÍA } \\
\text { MESETA } \\
\text { ORIENTAL }\end{array}$ & $\begin{array}{c}\text { ELEMENTOS } \\
\text { FILIACIÓN ENTRE } \\
\text { MESETA OR. Y C.U. } \\
\text { VALLE EBRO }\end{array}$ \\
\hline $\begin{array}{l}\text { CAMPOS DE } \\
\text { URNAS } \\
\text { (Sg. XII a. C.) }\end{array}$ & $\begin{array}{c}\text { Necrópolis organizadas } \\
\text { Incineración con estelas } \\
\text { Incineración-inhumación } \\
\text { bajo túmulos } \\
\text { Poblados en llano } \\
\text { Cerámica decoración } \\
\text { acanalada e incisa } \\
\text { Ausencia metal en ajuares } \\
\text { antiguos } \\
\text { Fíbula de pivote? } \\
\text { Cuenta de ámbar }\end{array}$ \\
\hline $\begin{array}{l}\text { ¿PROTOCELTIBÉ- } \\
\text { RICO, sg. VIII? }\end{array}$ & ¿? \\
\hline $\begin{array}{l}\text { CELTIBÉRICO } \\
\text { ANTIGUO } \\
\text { (Sg. VII-VI a.C) }\end{array}$ & $\begin{array}{c}\text { Rito incineración } \\
\text { Sepulturas en hoyo } \\
\text { Estructuras tumulares } \\
\text { Poblados en altura de "calle } \\
\text { central" } \\
\text { Viviendas rectangulares } \\
\text { adosadas } \\
\text { Morillos } \\
\text { Cerámica lisa de perfiles } \\
\text { bicónicos } \\
\text { Decoración excisa tipo } \\
\text { Roquizal } \\
\text { Cerámica a mano pintada } \\
\text { Fibulas de pivote }\end{array}$ \\
\hline
\end{tabular}

Tab. 3 .

En contraposición, vemos que sí están bien documentados los habitats tipo castro a partir de la fase Celtibérico Antiguo (siglos VII-VI a.C.) y se les puede considerar herederos de todas las tradiciones presentes en Cataluña y Bajo Aragón desde el Bronce Final, pudiéndose citar como ejemplo muy representativo al castro de El Ceremeño, situado en las inmediaciones de la necrópolis (Cerdeño y Juez
2002). Dicho castro está situado en el mismo término municipal de Herrería, a unos 500 m de distancia de la necrópolis, pero su primera ocupación es bastante más reciente que las fases antiguas del cementerio que ahora comentamos. La primera ocupación del poblado (Ceremeño I) parece corresponder a la fase más reciente de la necrópolis (Herrería III) y permite suponer que en momentos anteriores se eligieron zonas bajas para los asentamientos no fortificados, como parece ser el caso del mencionado Fuente Estaca o el de los poblados tipo Pico Buitre, situados en las vegas de los ríos.

\section{NUEVAS FECHAS RADIOMÉTRICAS}

El indudable interés de las dos ocupaciones antiguas de Herrería hacía imprescindible contar con dataciones radiocarbónicas que corroborasen la sincronía, por tanto la posible vinculación cultural, de sus conjuntos materiales con los grupos documentados en regiones cercanas y con los que acabamos de ver que mantiene evidentes paralelos formales. Sin otorgar a la cronología mayor prioridad que la que debe tener, consideramos importante conocer el tiempo real en que se sitúa la información manejada, en otras palabras "poner las cosas en su tiempo" (Castro et al. 1996), dado que ello permite establecer con mayor solvencia posibles sincronismos y conexiones entre ciertos acontecimientos del pasado. Con ello se evitarán imprecisiones a la hora de sistematizar y paralelizar yacimientos cuya adscripción a determinados períodos varía dependiendo de los esquemas tradicionales que en cada caso haga el autor del estudio correspondiente (Vázquez 2000: 87).

Hasta el momento hemos podido analizar cinco muestras correspondientes a las dos fases de utilización más antiguas. Los análisis se han realizado en el Centrum voor Isotopen Onderzoek de Gröningen (Holanda) que envía sus resultados en fechas no calibradas. Aunque son pocas muestras, su calibración ofrece datos de utilidad en el contexto de la discusión que aquí se presenta (1).

El primer análisis (GrN-25616) se realizó sobre una muestra de carbón procedente de la sepultura 44, sita en el nivel más antiguo de ocupación. Corresponde a un tramo en el que la curva de calibración tiene un comportamiento irregular. La inter-

(1) Agradecemos al profesor Gerardo Vega el comentario estadístico de las fechas calibradas. 
sección de la distribución original con dicha curva, a 1 sigma $(68,3 \%$ de probabilidad), genera una trasformada comprendida entre 1289 y $1129 \mathrm{cal}$. $\mathrm{BC}$ de comportamiento muy irregular. A 2 sigmas $(95,4 \%)$ el intervalo de calibración es 1371-1052 cal. BC. En esta situación, la mediana de la distribución transformada (1209 cal. BC) puede considerarse el estadístico más apropiado para estimar un valor central, con la ventaja de que está en el intervalo 1262-1206, al que corresponde el $48,1 \%$ de la probabilidad total.

\begin{tabular}{|c|c|c|c|}
\hline $\begin{array}{c}\text { NÚMERO } \\
\text { MUESTRA }\end{array}$ & PROCEDENCIA & $\begin{array}{c}\text { FECHA C-14 } \\
\text { BP }\end{array}$ & FECHA BC \\
\hline GrN-25616 & $\begin{array}{c}\text { Sep. 44. } \\
\text { (Herrería I) } \\
\text { Carbón }\end{array}$ & $2980 \pm 35$ & $\begin{array}{c}1030 \\
\text { (mediana cal. } \\
1209 \text { ) }\end{array}$ \\
\hline GrA-20603 & $\begin{array}{c}\text { Sep. 152. } \\
\text { (Herrería I) } \\
\text { Hueso cremado }\end{array}$ & $3010 \pm 50$ & $\begin{array}{c}1060 \\
\text { (mediana cal. } \\
1252 \text { ) }\end{array}$ \\
\hline GrA-20605 & $\begin{array}{c}\text { Sep. 183. } \\
\text { (Herrería I) } \\
\text { Hueso cremado }\end{array}$ & $3200 \pm 50$ & $\begin{array}{c}1250 \\
\text { (mediana cal. } \\
1473 \text { ) }\end{array}$ \\
\hline GrN-25217 & $\begin{array}{c}\text { Sep. 57. } \\
\text { (Herrería II) } \\
\text { Hueso } \\
\text { inhumación }\end{array}$ & $2705 \pm 55$ & $\begin{array}{c}755 \\
\text { (cal. } 831 \text { ) }\end{array}$ \\
\hline GrN-26942 & $\begin{array}{c}\text { Sep.222. } \\
\text { (Herrería II) } \\
\text { Hueso } \\
\text { inhumación }\end{array}$ & $2820 \pm 40$ & $\begin{array}{c}870 \\
\text { (mediana cal. } \\
961)\end{array}$ \\
\hline
\end{tabular}

Tab. 4. Dataciones obtenidas en Herrería.

La muestra n. ${ }^{\circ} 2$ (GrA-20603) era un fragmento de hueso humano cremado procedente de la sepultura 152/01, señalizada con una estela de piedra situada también en el nivel más antiguo de ocupación. Es la que tiene una intersección con la curva de calibración más irregular: a 1 sigma (intervalo 1371-1132 cal. BC) el 70,2\% de la probabilidad se corresponde a un pico comprendido entre $1317 \mathrm{y}$ 1210 cal. BC, mientras que a 2 sigmas el peso probabilístico mayor, $98,5 \%$, se encuentra entre 1403 y $1112 \mathrm{cal}$. BC y el resto se reparte en varios segmentos menores entre 1098 y 1053 cal. BC. Esta disimetría en la distribución calibrada hace que exista una diferencia significativa entre la mediana obtenida para el intervalo a 1 sigma (1252 cal. BC) o a 2 sigmas (1198 cal. BC).
La tercera muestra (GrA-20605), procedente de fragmentos de huesos humanos cremados de la sepultura 183/01 señalizada con una estela de piedra, ofrece un mejor ajuste en el intervalo de calibración. La mediana puede considerarse el estadístico de valor central más representativo de la distribución calibrada ( 1473 cal. BC, intervalo a 1 sigma 1517-1429 cal. BC, mientras la nueva curva presenta a 2 sigmas un trazado irregular, comprendido entre 1317-1210 cal. BC, aunque el 91,\% de la probabilidad se concentre entre 1543 y $1387 \mathrm{cal}$. BC.

Respecto a la cuarta muestra (GrN-25617), un fragmento de hueso del individuo inhumado en la sepultura 57/99-00, la situación es diferente puesto que la intersección directa de la media original sólo corresponde a un valor único de $831 \mathrm{cal}$. BC. A 1 sigma, el intervalo de calibración es también directo (898-814 cal. BC), mientras que a 2 sigmas el intervalo 944-795 cal. BC corresponde al 95,6\% de la probabilidad, mientras que entre 995 y 955 quedan un par de picos que sólo representan el 4,4\% de la distribución. En este caso es innecesario utilizar la mediana ( $854 \mathrm{cal}$. BC) como estadístico de valor central, ya que la intersección directa de la media original es prácticamente igual.

El quinto análisis (GrN-26942) se realizó sobre un fragmento de hueso del cuerpo inhumado en la sepultura 222/01, señalizada por un gran túmulo de piedra. La muestra ofrece un buen ajuste en el intervalo de calibración 1010-912 cal. BC. a 1 sigma, mientras que a 2 sigmas la curva presenta varios picos entre 1125-830 cal. BC., aunque el segmento comprendido entre 1053 y $892 \mathrm{cal}$. BC. representa el $89,9 \%$ de la distribución; en este caso vuelve a ser útil usar la mediana de la distribución a 1 sigma como valor central de la muestra (961 cal. BC), muy similar a la que se obtendría para el recorrido a 2 sigmas ( 982 cal. BC).

Los valores ofrecidos por las muestras de los niveles más antiguos de Herrería coinciden plenamente con las fechas obtenidas en los últimos años en numerosos yacimientos de Campos de Urnas catalanes y aragoneses, al igual que en algunos del alto Ebro (Tab. 5), cuyas fases iniciales se enmarcan entre 1330-1070 (Castro et al. 1996: 182). Del mismo modo, quedan incluidas en los límites de las dataciones europeas calibradas dendrocronológicamente que proponen situar los límites de los Campos de Urnas clásicos entre 1365 y 740 BC (Neumaier 1995: 53). 


\begin{tabular}{|c|c|}
\hline Poblado de Carretelá (Le) & $3040=1090(1310$ cal. $)$ \\
\hline Poblado de Genó (Le) & $\begin{array}{c}2970 \pm 54=1020(1210 \\
\text { cal. }) \\
2860 \pm 90=910(1067 \\
\text { cal. }) \\
2815 \pm 45=865(929 \text { cal. })\end{array}$ \\
\hline $\begin{array}{c}\text { Poblado de Palermo }(\mathrm{Za}) \\
\text { III } \\
\text { II } \\
\end{array}$ & $\begin{array}{c}2980=1030 \\
2800=850\end{array}$ \\
\hline $\begin{array}{l}\text { Necr. de Los Castellets } \\
\text { (Za) }\end{array}$ & $\begin{array}{c}3040 \pm 140=1090(1280 \\
\text { cal. }) \\
2820 \pm 30=870(974 \text { cal. }) \\
2780 \pm 35=830(946 \text { cal. }) \\
2755 \pm 30=805 \text { (904 cal. })\end{array}$ \\
\hline $\begin{array}{l}\text { Poblado de Fuente Estaca } \\
\qquad(\mathrm{Gu})\end{array}$ & $2750 \pm=800(919$ cal. $)$ \\
\hline $\begin{array}{l}\text { Poblado de Pico Buitre } \\
\text { (Gu) }\end{array}$ & $\begin{array}{c}2990 \pm 90=1040(1238 \\
\text { cal. }) \\
2900 \pm 90=950(1112 \\
\text { cal. })\end{array}$ \\
\hline
\end{tabular}

Tab. 5. Dataciones de otros yacimientos del Bronce Final.

\section{CONSIDERACIONES PROVISIONALES}

Como decíamos al principio, los datos expuestos en estas líneas creemos que constituyen una interesante información sobre la llegada del ritual incinerador a los territorios de la Meseta oriental más próximos a Aragón.

La fase más antigua de la necrópolis (Herrería I) puede fecharse en torno al siglo XIII cal. a.C. y demuestra que la incineración estaba ya perfectamente implantada como ritual exclusivo en una necrópolis organizada y señalizada con estelas. Debido a la escasez de datos acerca de las etapas locales del Bronce Final, no podemos asegurar si dichos hitos funerarios eran una reminiscencia de antiguas tradiciones locales o si también eran producto, al igual que el ritual, de las nuevas influencias culturales. La segunda fase de utilización (Herrería II), fechada en el siglo IX cal. a.C., mantiene numerosos paralelos formales con las necrópolis de incineración tumulares del grupo ilerdense y bajoaragonés y, al igual que en el caso anterior, con cronologías muy similares.

Estos datos son suficientemente expresivos y novedosos como para poder mantener la hipótesis de que grupos de Campos de Urnas, no sólo sus influencias materiales dado el escaso substrato cul- tural preexistente, alcanzaron el reborde oriental de la Meseta donde se establecieron e iniciaron una ocupación permanente y duradera cuyo recuerdo se constata en el registro a lo largo de toda la Edad del Hierro. El acceso desde el valle del Ebro hasta esta zona meseteña es perfectamente practicable si se utilizan las vías de acceso proporcionadas por los afluentes del río Jalón en su margen derecha (Jiloca, Mesa o Piedra, estos dos últimos con su nacimiento en la comarca molinesa y con yacimientos antiguos en sus valles) o las rutas terrestres a partir de las cabeceras de otros afluentes del Ebro, como el Huerva o el Martín.

Todavía habrá que matizar numerosos aspectos de este planteamiento, pues mucho se ha discutido sobre la significación o el auténtico contenido cultural que tuvieron los Campos de Urnas en regiones que, como la propia Península Ibérica, se consideraron marginales a su originario lugar de procedencia, hasta el punto de que algunos autores han subrayado la existencia de culturas "periféricas" a la influencia de los Campos de Urnas en regiones occidentales como el Macizo francés, el Languedoc o los Pirineos (Hatt 1988: 176). Sin embargo, se acepta mayoritariamente que los Campos de Urnas del suroeste europeo pertenecen plenamente a la cultura de los centroeuropeos aunque, por supuesto, existen diferencias debidas a la propia evolución interna de cada uno de estos grupos (Neumaier 1995: 66).

Proponemos la vinculación del territorio meseteño oriental a este ambiente cultural por la ocupación de nuevos paisajes, la presencia generalizada del ritual incinerador y la de algunos tipos cerámicos aunque de momento falten las determinantes formas acanaladas documentadas en el área del Nordeste, hasta ahora solo documentadas en nuestra zona en el mencionado poblado de Fuente Estaca. Los hallazgos de la necrópolis de Herrería suponen una interesante aportación que ayuda a clarificar este proceso cultural, sobre todo cuando finalice el estudio completo del yacimiento y podamos manejar una información más amplia. La presencia generalizada del ritual incinerador en territorio meseteño en fechas tan elevadas abre un abanico de posibilidades interpretativas al demostrar la llegada de las nuevas costumbres rituales antes que la de otros elementos materiales, al tiempo que la existencia de señalizaciones de piedra bien estratificadas, estelas y túmulos, puede permitir investigar sobre su origen y desarrollo a lo largo de un amplio período de tiempo. 


\section{BIBLIOGRAFÍA}

ALMAGRO BASCH, M. 1952: "La invasión céltica en España”. En Menéndez Pidal (ed.), Historia de España, 1, II: 141-240. Madrid.

ALMAGRO GORBEA, M. 1977: "El Pic dels Corbs en Sagunto y los Campos de Urnas del Noreste de la Península Ibérica" Saguntum 12: 88-141.

ARENAS, J.A. 1999: La Edad del Hierro en el sistema Ibérico Central. España. British Archaeological Report International Series, 780. Oxford.

BARROSO, R. 1993: "El Bronce Final y la transición a la Edad del Hierro en Guadalajara". Wad-Al-Hayara 20: 9-44.

- 1999: "Notas sobre el Bronce Final y los comienzos de la Edad del Hierro en el valle alto del Tajo: la provincia de Guadalajara". II Congreso de Arqueología Peninsular (Zamora 1996), III: 153-160. Palencia. Alcalá de Henares.

BELTRÁN, A. 1960: "La indoeuropeización del valle del Ebro”. I Symposium de Prehistoria Peninsular. Pamplona.

- 1963: "Los poblados hallstatticos de Caspe y los problemas cronológicos de la cultura del Bajo Aragón". Homenaje al profesor Bosch Gimpera. México: 41-48.

BOSCH GIMPERA, P. 1921: "Los celtas y la civilización céltica de la Península Ibérica”. Boletín de la Sociedad Española de Excursiones 29: 248-300.

- 1939: "Two celtic waves in Iberia". Proceedings of the Britihs Academy XXVI: 1-126. Oxford.

CASTRO, P.V.; LULL, V. y MICÓ, R. 1996: Cronología de la Prehistoria Reciente de la Península Ibérica y Baleares (c. 2800-900 cal ANE). BAR, International Series, 652. Oxford.

CERDEÑO, $M^{\mathrm{a}}$ L. 1985-86: "Una fecha de C-14 para los Campos de Urnas de la Meseta oriental". Zephyrus XXXIX-XL: 113-117.

CERDEÑO, M²L. y GARCÍA HUERTA, R. 1992: El castro de La Coronilla (Chera, Guadalajara). Excavaciones Arqueológicas en España 69. Ministerio de Cultura. Madrid.

CERDEÑO, Ma'L. y JUEZ, P. 2002: El castro celtibérico de El Ceremeño (Herrería, Guadalajara). Monografías Arqueológicas del S.A.E.T., 8. Teruel.

CERDEÑO, ML., MARCOS, F. y SAGARDOY, T.: "Noticia preliminar sobre la necrópolis de Herrería (Guadalajara)". I Symposium de Arqueología de Guadalajara. Sigüenza: 425-434.

CRESPO, MaL. y CUADRADO, M.A. 1990: "Dos nuevos yacimientos de tipo "Pico Buitre" en el valle del Henares (Guadalajara)". Wad-Al-Hayara 17: 67-93.

EIROA, J.J. (1982): La Loma de los Brunos y los Campos de Urnas del Bajo Aragón. Institución Fernando El Católico. Zaragoza.

FERRANDEZ, M.; LAFUENTE, A.; LÓPEZ, J.B. y PLENS, M. 1991: "La necrópolis tumular d'incinera- ció de La Colomina 1 (Gerb, La Noguera)". Revista d'Arqueología de Ponent 1: 83-150.

GALÁN, E. 1994: "Estelas y fronteras: un caso de estudio en el Bajo Aragón en época ibérica". V Congreso Internacional de Estelas Funerarias: 99-106. Soria.

GARCÍA HUERTA, R. 1989: La Edad del Hierro en la comarca del Alto Jalón-Alto Tajo. Tesis doctorales. Universidad Complutense de Madrid.

GARCÍA LÓPEZ, E. 1994: “Un modelo de análisis de evolución arquitectónica e interpretación social. El asentamiento del Bronce Final-Primera Edad del Hierro del Alto de la Cruz (Cortes, Navarra)". Pyrenae 25: 93-110.

GONZÁLEZ PRATS, A. 2002: "La necrópolis de incineración de Les Moreres (Crevillente, Alicante, España), siglos IX-VII a. C". Edición III Seminario Internacional sobre Temas Fenicios. Alicante.

HATT, J.J. 1988: "Invasion ou acculturation? Conditions régionales de la diffusion de la culture des Champs d'Urnes en France". En P. Brun y C. Mordant (dirs.): Le groupe Rhin-Suisse-France Orientale et la notion de la civilisation de Champs d'Urnes. Mémoires du Musée d'Ille de France. Nemours: 173-177.

MALUQUER, J. 1945-46: "Las culturas hallstáticas en Cataluña". Ampurias VII-VIII: 115-184.

- 1954a: "La Edad del Hierro en la cuenca del Ebro y Meseta Central española". IV Congreso Internacional de Ciencias Pre y Protohistóricas: 5-28. Madrid.

- 1954b: El yacimiento hallstáttico de Cortes de Navarra. Estudio Crítico I. Pamplona.

- 1958: El yacimiento hallstáttico de Cortes de Navarra. Estudio Crítico II. Pamplona.

- 1971: "Late Bronze Age and Early Iron Age in the valley of the Ebro". Homenaje a C.F.C. Hawkes. London.

MARTÍNEZ NARANJO, J.P. 1997: "El inicio del mundo celtibérico en el interfluvio en el Alto Jalón-Mesa". Complutum 8: 161-182.

MARTÍNEZ SASTRE, V. 1992: "El poblado de Campos de Urnas de Fuente Estaca (Embid, Guadalajara)”. En J. Valiente (ed.): La celtización del Tajo Superior. Universidad de Alcalá de Henares. Alcalá de Henares: 67-78.

MAYA, J.L. 1978: "Las necrópolis tumulares ilerdenses. Els pobles preromans del Pirineu". $2^{\circ} \mathrm{Col}$-loqui Internacional d'Arqueologia de Puigcerdá: 83-96. Puigcerdá.

- 1998: "El Bronce Final y los inicios de la Edad del Hierro". En I. Barandiarán, B. Martí, Mª A. Rincón y J.L. Maya (eds.): Prehistoria de la Península Ibérica. Ariel. Barcelona: 317-425.

MAYA, J.L.; CUESTA, F. y LÓPEZ-CACHERO, J. (eds.) 2000: Genó: un poblado de la Edad del Bronce en el Bajo Segre (Lleida). Universidad de Barcleona.

MUNILLA, F. y GRACIA, F. 1995: "Evolución arquitectónica del poblado protohistórico del Alto de la Cruz (Cortes, Navarra)". III Symposium sobre Los Celtíberos. El poblamiento celtibérico: 41-57. Zaragoza.

NEUMAIER, J. 1995: "Los Campos de Urnas del sudoes-

T. P., 59, n. ${ }^{\circ} 2,2002$ 
te europeo desde el punto de vista centroeuropeo". Revista d'Arqueologia de Ponent 5: 53-80.

PELLICER, M. 1987: "Hacia una revisión de los yacimientos protohistóricos de la comarca de Caspe (Zaragoza)". Caesaraugusta 64: 157-188.

PONS, E. 1989: "The beginning of the first Iron Age in Catalonia, Spain". En M ${ }^{\mathrm{a}} \mathrm{L}$. Sting Sörensen y R. Thomas (eds.): The Bronze Age-Iron Age Transition in Europe. BAR International Series, 483 (i). Oxford.

PONS, E. y MAYA, J.L. 1988: "L'Age du Bronze Finale en Catalogne". En P. Brun y C. Mordant (dirs.): La groupe Rhin-Suisse-France Orientale et la notion de civilisation des Champes d'Urnes. Mémoires du Musée d'Ille de France. Nemours: 545-557.

RAFEL, N. 1991: La necrópolis del Coll del Moro. Gandesa, Terra Alta. Campanyes 1984 a 1987. Generalitat de Catalunya. Dpto. de Cultura. Barcelona.

RAFEL, N. y HERNÁNDEZ, G. 1992: "Practiques funeráries a la necrópolis del Coll del Moro (Gandesa, La Terra Alta)". Revista d'Arqueologia de Ponent 2: 37-57.

ROVIRA, J. 1991: "Reflexiones sobre los primeros Campos de Urnas en la Península Ibérica: una arribada marítima". Cuadernos de Prehistoria y Arqueología Castellonense 15: 157-171.

ROYO, J.I. 1994-96: "Ritual funerario y cultura material en las necrópolis tumulares de Los Castellets de Mequinenza (Zaragoza): Una aportación al estudio del Bronce Final/Hierro I en el Noreste peninsular". Gala 3-5: 93108.
- 1990: "Las necrópolis de Campos de urnas del bajo Aragón como precedentes del mundo funerario celtibérico". II Symposium sobre Los Celtíberos. Necrópolis de incineración: 123-136. Zaragoza.

- 1994: "Estelas y cipos funerarios en la necrópolis tumular de Los Castellets de Mequinenza (Zaragoza, España)". V Congreso Internacional de Estelas Funerarias: $117-134$. Soria.

RUIZ ZAPATERO, G. 1985: Los Campos de Urnas del Nordeste de la Península Ibérica. Tesis Doctoral, 83/ 85. Universidad Complutense de Madrid.

- 2001: "Las sociedades del Bronce Final: enterramientos y sociedad en los Campos de Urnas". En M. RuizGálvez (coord.): La Edad del Bronce. ¿Primera Edad de Oro de España?. Crítica. Barcelona: 257-288.

THOMAS, L-V. 1975: Antropología de la muerte. Fondo de Cultura Económico. Méjico.

TOVAR, A. 1957: "Las invasiones indoeuropeas: problema estratigráfico". Zephyrus VIII, 1: 77-83.

VALIENTE, J. 1984: "Pico Buitre (Espinosa de Henares, Guadalajara). La transición del Bronce al Hierro en el Alto Henares". Wad-Al-Hayara 11: 9-57.

VALIENTE, J. y VELASCO, M. 1986: “El cerro Almudejo (Sotodosos, Guadalajara): Un asentamiento de transición Bronce al Hierro". Wad-Al-Hayara 13: 71-90.

VÁZQUEZ, Mª. 2000: "Les necrópolis dels camps d'urnes del bronze, ferro i època ibérica del Baix Segr. Aspects cronologics i rituals". Revista d'Arqueologia de Ponent 10: 65-101. 